\title{
Stage IIA Ampulla of Vater Cancer AJCC v7
}

National Cancer Institute

\section{Source}

National Cancer Institute. Stage IIA Ampulla of Vater Cancer A/CC v7. NCI Thesaurus.

Code C88098.

Stage IIA includes: T3, N0, M0. T3: T umor invades the pancreas. N0: No regional lymph node metastasis. M0: No distant metastasis. (from AJCC 7th Ed.) 